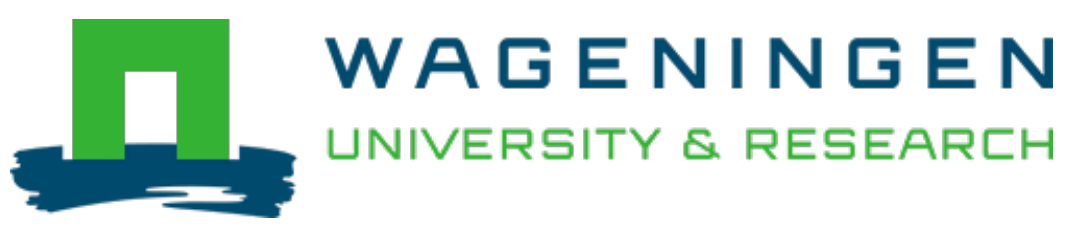

\title{
Intercropping maize and soybean increases efficiency of land and fertilizer nitrogen use; A meta-analysis
}

\section{Field Crops Research}

Xu, Zhan; Li, Chunjie; Zhang, Chaochun; Yu, Yang; Werf, Wopke et al https://doi.org/10.1016/j.fcr.2019.107661

This publication is made publicly available in the institutional repository of Wageningen University and Research, under the terms of article $25 \mathrm{fa}$ of the Dutch Copyright Act, also known as the Amendment Taverne. This has been done with explicit consent by the author.

Article 25 fa states that the author of a short scientific work funded either wholly or partially by Dutch public funds is entitled to make that work publicly available for no consideration following a reasonable period of time after the work was first published, provided that clear reference is made to the source of the first publication of the work.

This publication is distributed under The Association of Universities in the Netherlands (VSNU) 'Article $25 \mathrm{fa}$ implementation' project. In this project research outputs of researchers employed by Dutch Universities that comply with the legal requirements of Article $25 \mathrm{fa}$ of the Dutch Copyright Act are distributed online and free of cost or other barriers in institutional repositories. Research outputs are distributed six months after their first online publication in the original published version and with proper attribution to the source of the original publication.

You are permitted to download and use the publication for personal purposes. All rights remain with the author(s) and / or copyright owner(s) of this work. Any use of the publication or parts of it other than authorised under article $25 \mathrm{fa}$ of the Dutch Copyright act is prohibited. Wageningen University \& Research and the author(s) of this publication shall not be held responsible or liable for any damages resulting from your (re)use of this publication.

For questions regarding the public availability of this publication please contact openscience.library@wur.nl 


\title{
Intercropping maize and soybean increases efficiency of land and fertilizer nitrogen use; A meta-analysis
}

\author{
Zhan $\mathrm{Xu}^{\mathrm{a}, \mathrm{c}}$, Chunjie $\mathrm{Li}^{\mathrm{a}}{ }^{\mathrm{a}, \mathrm{c}}$, Chaochun Zhang ${ }^{\mathrm{a}, \mathrm{c}, *}$, Yang $\mathrm{Yu}^{\mathrm{b}, \mathrm{c}}$, Wopke van der Werf ${ }^{\mathrm{b}, \mathrm{c}}$, \\ Fusuo Zhang ${ }^{\mathrm{a}, \mathrm{c}}$ \\ ${ }^{\text {a }}$ College of Resources and Environmental Sciences, China Agricultural University, Beijing 100193, China \\ ${ }^{\mathrm{b}}$ Centre for Crop Systems Analysis, Wageningen University, P.O. Box 430, 6700 AK, the Netherlands \\ ${ }^{\mathrm{c}}$ Soil Biology Group, Wageningen University, Drovevendaalsesteeg 3, 6708 PB, the Netherlands
}

\section{A R T I C L E I N F O}

\section{Keywords:}

Maize

Soybean

Intercropping

Land equivalent ratio (LER)

Fertilizer N equivalent ratio (FNER)

\begin{abstract}
A B S T R A C T
Intercropping exploits species complementarities to achieve sustainable intensification by increasing crop outputs per unit land with reduced anthropogenic inputs. Cereal/legume intercropping is a classical case. We carried out a global meta-analysis to assess land and fertilizer $\mathrm{N}$ use efficiency in intercropping of maize and soybean as compared to sole crops, based on 47 studies reported in English and 43 studies reported in Chinese. The data were extracted and analyzed with mixed effects models to assess land equivalent ratio (LER) of intercropping and factors affecting LER. The worldwide average LER of maize/soybean intercropping was $1.32 \pm 0.02$, indicating a substantial land sparing potential of intercropping over sole crops. This advantage increased as the temporal niche differentiation between the two species was increased by sowing or harvesting one crop earlier than the other as in relay intercropping, i.e. with only partial overlap of the growing periods of the two species The mean fertilizer $\mathrm{N}$ equivalent ratio (FNER) was $1.44 \pm 0.03$, indicating that intercrops received substantially less fertilizer $\mathrm{N}$ than sole crops for the same product output. These fertilizer savings are mainly due to the high relative maize yield and the lower $\mathrm{N}$ input in the intercrop compared to the input in sole maize. This meta-analysis thus shows that exploiting species complementarities by intercropping maize and soybean enables major increases in land productivity with less fertilizer $\mathrm{N}$ use. Both LER and FNER increased as the difference in growth duration increased for maize and soybean, but were not affected by fertilizer N rate. LER increased when soil organic matter increased but FNER did not change with soil organic matter.
\end{abstract}

\section{Introduction}

In the $21^{\text {th }}$ century, the major challenge of agriculture is to reconcile these two needs: increasing food production while lowering environmental pollution (Matson et al., 1997; Wittwer et al., 2017). Intensive farming contributes much to crop production, but it meanwhile leads to negative consequences because of high chemical inputs and low biodiversity (Giller et al., 1997; Tilman et al., 2002; Guo et al., 2010; Liu et al., 2013). Intercropping has recently been called the "new green revolution" since it has the potential to raise land productivity by exploiting species complementarities, and provide an opportunity to achieve sustainable intensification of agriculture (Martin-Guay et al., 2018). However, adoption of intercropping in the developed world is slow. On the other hand, intercropping is a main way of production for smallholders in comparatively underdeveloped areas (Snapp et al.,
2010; Ngwira et al., 2012; Rusinamhodzi et al., 2012; Huang et al., 2015).

Maize is one of the most important food crops in the world. It was grown on a global acreage of 228 million ha in 2016 (FAO, $2018 \mathrm{http}: / /$ www.fao.org/faostat/en/\#data/QC). Soybean is an important source of plant-derived protein in animal feed and accounts for more than half of the world's oil production (Ainsworth et al., 2012).

Land and water resources are lacking to expand soybean production area in major producing countries such as the United States and Brazil. Soybean cultivation is regarded as one of the underlying direct causes of tropical deforestation (Barona et al., 2010). Here, we argue that maize/soybean intercropping has the potential to solve the conundrum of maintaining or even increasing maize and soybean production, while using less land and reducing environmental impact.

Intercropping is an effective way to increase system productivity

\footnotetext{
*Corresponding author at: College of Resources and Environmental Science, China Agricultural University, 100193, No.2 Yuanmingyuan West Road, Haidian District, Beijing, China.

E-mail address: zhangcc@cau.edu.cn (C. Zhang).
} 
Table 1

Variables extracted from publications.

\begin{tabular}{|c|c|c|}
\hline Variable & Definition & Data type/Unit \\
\hline Title & Title of publication & Text \\
\hline Authors & Authors of Publication & Text \\
\hline Continent & Continent where experiments were carried out & Text \\
\hline Country & Country where experiments were carried out & Text \\
\hline Latitude and longitude & Latitude and longitude of the experimental site & Text \\
\hline Sowing and harvesting date & $\begin{array}{l}\text { Sowing and harvesting date of intercropped species or information on total period and overlap period of intercrops to calculate } \\
\text { TND }\end{array}$ & Date \\
\hline Rate of $\mathrm{N}$ fertilization & Amount of $\mathrm{N}$ fertilizer applied to sole crops and to intercrops per unit area of the whole field & $\mathrm{kg} / \mathrm{ha}$ \\
\hline Organic matter & Organic matter of the soil at the experimental site & $\mathrm{g} / \mathrm{kg}$ \\
\hline Row spacing & Row spacing of each species in sole crops and in the intercrop & $\mathrm{m}$ \\
\hline Yield & Grain yield of sole crops and intercrops & ton/ha \\
\hline
\end{tabular}

(Yu et al., 2015). It enhances farmland biodiversity and increases utilization efficiencies of resources, i.e. land, nutrients, light and water (Clark and Francis, 1985; Li et al., 2001a; Good et al., 2004; Zhang et al., 2007, 2008a, b; Li et al., 2009). However, trade-offs exist. In many maize/soybean intercrop systems, soybean is shaded and therefore yields less than sole crops (Wolff and Coltman, 1989; Wu et al., 2016). Studies on maize/soybean strip intercropping in the USA found that maize plants in intercrops had approximately $25 \%$ more yield than maize plants in sole crops, while soybean yield in rows that were immediately adjacent to maize was reduced by $10 \%$ to $27 \%$ (West and Griffith, 1992; Ghaffarzadeh et al., 1994). However, yield in maize/ soybean intercropping varies from study to study and a synthesis of existing data is required to assess the benefits of intercropping maize and soybean using all the available information across the world.

Previous meta-analyses of land equivalent ratio in intercropping indicate that the average LER is around 1.22 (Yu et al., 2015) to 1.30 (Martin-Guay et al., 2018). These previous studies are global metaanalyses, but they consider a wide range of species combinations, with only a small sample of studies on maize/soybean intercropping, e.g. seven out of 100 publications in the study of Yu et al. (2015) and 66 out of 939 data records (126 publications) in Martin-Guay et al. (2018). No meta-analysis has been made of the potential yield advantages that might be achieved by intercropping maize and soybean. Because of the global importance of these crop species, we conducted a specific metaanalysis on the land equivalent ratio in maize/soybean intercropping. Land equivalent ratio is used in this analysis because it expresses the potential land sparing of intercropping as compared to sole crops (Mead and Willey, 1980). Furthermore, we use here a related and new metric, fertilizer nitrogen equivalent ratio (FNER), to express how intercropping can spare fertilizer resources. We address two main questions: (1) What is globally the land equivalent ratio and fertilizer $\mathrm{N}$ equivalent ratio of maize/soybean intercropping? (2) How are LER and FNER affected by management of the intercropping systems, particularly, the use of simultaneous or relay-intercropping, input of fertilizer $\mathrm{N}$, and soil organic matter?

\section{Materials and methods}

\subsection{Data collection and extraction from the publication}

We searched for relevant publications using the terms ("Maize" or "Corn") and "Soybean" and "Intercrop", in the topic field in three databases: CNKI (http://www.cnki.net/), WanFang DATABASE (http:// g.wanfangdata.com.cn/index.html) and Web of Science (http://apps. webofknowledge.com/). The set of publications was refined by selecting publications mentioning "Nitrogen", "Grain yield" and "Field" in the topic field. In Web of Science, we searched literature published from 1980 to 2018, and obtained in total 265 publications including 12 publications published in Chinese which were included from this subdataset. In a second screening we excluded reviews and conference papers, studies focusing on diseases and weeds, and some studies withreporting problem, e.g. missing sole crop yield, without intercropping configuration information, a reported LER value different for from the one calculated from the yield, or incorrect experiment design. At the end, we collected 42 English-language publications from Web of Science. A similar selection process was applied to the search result obtained from the CNKI and WanFang Databases. In the CNKI, we first obtained 118 publications, including the 12 publications written in Chinese which were excluded from search result of Web of Science. After the second screening, 43 publications remained from CNKI. Of those, 38 were peer reviewed, 4 were MSc theses, and 1 was a $\mathrm{PhD}$ thesis. From the WanFang Database, we collected 3 MSc theses. English publications are those written in Englishwhile Chinese publications are those of which the main text is written in Chinese. The selected 88 publications included 80 that were peer-reviewed, (42 publications written in English were from Web of Science, and 38 publications written in Chinese were from CNKI), seven MSc theses and $1 \mathrm{PhD}$ dissertation (Appendix: Table S1). Data were extracted from tables or from figures using the GetData Graph Digitizer version 2.26. We built a database with 654 records, i.e. an average of 7.4 records per publication. Different data records from the same publication represent separate experiments and different treatments within an experiment.

For each experiment, we collected basic information on the experimental site, such as soil properties (soil organic matter, SOM) and geographic location. For each treatment, we retrieved the data on grain yield for the intercrop and sole crops per matching management as defined by fertilizer $\mathrm{N}$ amount, sowing and harvesting date, row spacing and plant density (Appendix: Methods S1 and Table S2). Four Chinese publications mentioned that compound fertilizer was used but did not mention its composition. In this case, we assumed relative proportions of $\mathrm{N}: \mathrm{P}_{2} \mathrm{O}_{5}: \mathrm{K}_{2} \mathrm{O}$ of $15: 15: 15$, which is the fertilizer that is most commonly used by farmers (Zhang et al., 2008a, b), i.e. the compound fertilizer contained $15 \%$ weight pure N, $15 \%$ pure $\mathrm{P}_{2} \mathrm{O}_{5}$ and $15 \%$ pure $\mathrm{K}_{2} \mathrm{O}$. Table 1 summarizes which data were extracted.

Intercropping pattern included strip intercropping, row intercropping and mixed intercropping. Strip intercropping refers to growing two or more crops together in strips wide enough to permit separate crop management using machines but close enough for the individuals of different plant species to interact, row intercropping refers growing two or more crops simultaneously with one or more crops planted in rows, and mixed intercropping refers growing two or more crops together in no distinct row arrangement (Gliessman, 1983; Sullivan, 2003). In mixed intercropping, maize and soybean received the same fertilizer. For row and strip intercropping, the publications specified the amount of fertilizer $\mathrm{N}$ applied to intercrops and sole crops.

\subsection{Response variables}

The analyses included four response variables, i.e. LER (Mead and Willey, 1980), partial land equivalent ratio (pLER), FNER, and intercrop soybean yield proportion. Metrics comparing sole crops and intercrops were based on same management of pests, irrigation, diseases 
Table 2

Specification of the mixed effects models fitted to the data. The indices $i, j$ and $k$ represent publication ID, experiment ID and treatment ID, respectively. In all mixed effects models (models $1-14), a_{i}$ is a random publication effect. $b_{i j}$ is a random experiment effect nested within the $i^{\text {th }}$ publication. $a_{i}$ and $b_{i j}$ are assumed normally distributed with constant variances. $\varepsilon_{i j k}$ is a residual random error assumed normally distributed with constant variance. The variance terms $\mathrm{a}_{i}, \mathrm{~b}_{i j}$ and $\varepsilon_{i j k}$ are all assumed independent. In models 3 and 4 the superscripts 2,3,4...7 indicate different continents while the supercript 2 in models 13 and 14 means a different fertilizer $\mathrm{N}$ input situation.

\begin{tabular}{|c|c|}
\hline Model & Equations \\
\hline 1 & $\mathrm{LER}_{i j k}=\beta_{0}+\mathrm{a}_{i}+\mathrm{b}_{i j}+\varepsilon_{i j k}$ \\
\hline 2 & $\mathrm{FNER}_{i j k}=\beta_{0}+\mathrm{a}_{i}+\mathrm{b}_{i j}+\varepsilon_{i j k}$ \\
\hline 3 & LER $_{i j k}=\beta_{0}+\beta_{1}{ }^{*}$ continent $_{i}^{2}+\beta_{2}{ }^{*}$ continent $_{i}^{3}+\beta_{3}{ }^{*}$ continent $_{i}^{4}+\beta_{4}{ }^{*}$ continent $_{i}^{5}+\beta_{5}{ }^{*}$ continent $_{i}^{6}+\beta_{6}{ }^{*}$ continent $_{i}^{7}+\mathrm{a}_{i}+\mathrm{b}_{i j}+\varepsilon_{i j k}$ \\
\hline 4 & FNER $_{i j k}=\beta_{0}+\beta_{1}{ }^{*}$ continent $_{i}^{2}+\beta_{2}{ }^{*}$ continent $_{i}^{3}+\beta_{3}{ }^{*}$ continent $_{i}^{4}+\beta_{4}{ }^{*}$ continent $_{i}^{5}+\beta_{5}{ }^{*}$ continent $_{i}^{6}+\beta_{6}{ }^{*}$ continent $_{i}^{7}+\mathrm{a}_{i}+\mathrm{b}_{i j}+\varepsilon_{i j k}$ \\
\hline 5 & $\mathrm{LER}_{i j k}=\beta_{0}+\beta_{1}{ }^{*} \mathrm{TND}_{i j k}+\mathrm{a}_{i}+\mathrm{b}_{i j}+\varepsilon_{i j k}$ \\
\hline 6 & $\mathrm{FNER}_{i j k}=\beta_{0}+\beta_{1} * \mathrm{TND}_{i j k}{ }^{2}+\beta_{2}{ }^{*} \mathrm{TND}_{i j k}+\mathrm{a}_{i}+\mathrm{b}_{i j}+\varepsilon_{i j k}$ \\
\hline 7 & $\mathrm{LER}_{i j k}=\beta_{0}+\beta_{1} * \mathrm{SOM}_{i j k}+\mathrm{a}_{i}+\mathrm{b}_{i j}+\varepsilon_{i j k}$ \\
\hline 8 & $\mathrm{FNER}_{i j k}=\beta_{0}+\beta_{1} * \mathrm{SOM}_{i j k}+\mathrm{a}_{i}+\mathrm{b}_{i j}+\varepsilon_{i j k}$ \\
\hline 9 & $\mathrm{LER}_{i j k}=\beta_{0}+\beta_{1} * \mathrm{~N}_{i j k}+\mathrm{a}_{i}+\mathrm{b}_{i j}+\varepsilon_{i j k}$ \\
\hline 10 & $\operatorname{pLER}_{i j k}=\beta_{0}+\beta_{1}{ }^{*} \mathrm{~N}_{i j k}+\mathrm{a}_{i}+\mathrm{b}_{i j}+\varepsilon_{i j k}$ \\
\hline 11 & pLER $2_{i j k}=\beta_{0}+\beta_{1} * N_{i j k}+a_{i}+b_{i j}+\varepsilon_{i j k}$ \\
\hline 12 & Proportion $_{i j k}=\beta_{0}+\beta_{1} * \mathrm{~N}_{i j k}+\mathrm{a}_{i}+\mathrm{b}_{i j}+\varepsilon_{i j k}$ \\
\hline 13 & $\mathrm{LER}_{i j k}=\beta_{0}+\beta_{1} * \mathrm{~N}_{i}^{2}+\mathrm{a}_{i}+\mathrm{b}_{i j}+\varepsilon_{i j k}$ \\
\hline 14 & $\mathrm{FNER}_{i j k}=\beta_{0}+\beta_{1} * \mathrm{~N}_{i}^{2}+\mathrm{a}_{i}+\mathrm{b}_{i j}+\varepsilon_{i j k}$ \\
\hline
\end{tabular}

and weeds, and same sowing date. The first two variables were calculated according to the Eqs. (1) and (2).

LER $=\frac{Y_{1}}{M_{1}}+\frac{Y_{2}}{M_{2}}$

$\mathrm{pLER}_{1}=\frac{Y_{1}}{M_{1}} \& \mathrm{pLER}_{2}=\frac{Y_{2}}{M_{2}}$

Where $Y_{1}$ and $Y_{2}$ are the yields (per unit of total area of the intercrop) of maize (species 1) and soybean (species 2) and $M_{1}$ and $M_{2}$ are the corresponding sole crop yields (per unit area of the sole crop).

By analogy with land equivalent ratio (LER) and water equivalent ratio (Mao et al., 2012), we define FNER as the amount of fertilizer $\mathrm{N}$ used in sole crops to produce the same yield as obtained in intercropping, and used Eq. (3) to calculate it:

FNER $=\frac{N f_{1} \times \frac{Y_{1}}{M_{1}}+N f_{2} \times \frac{Y_{2}}{M_{2}}}{N f_{\text {IC }}}=\mathrm{pLER}_{1} \times \frac{N f_{1}}{N f-\text { IC }}+\mathrm{pLER}_{2} \times \frac{N f_{2}}{N f_{\text {IC }}}$

Where $N f_{I C} N f_{I}$ is the fertilizer $\mathrm{N}$ per unit area of the intercrop, and $N f_{1}$, $N f_{2}$ are the fertilizer $\mathrm{N}$ of maize or soybean in monoculture crops (per unit area of the respective sole crop). FNER will be equal to the LER is the fertilizer input in the intercrops is equal to that in the sole crops. If, however, the fertilizer input in the intercrop is intermediate between that in the sole crops (e.g. a weighted average according to the proportions of the area sown with each species), FNER could be different from LER, particularly if one species has a greater relative yield than the other. In maize-legume intercrops, maize (comparatively dominant) has often a larger pLER than the legume (dominated). In such a case, $\mathrm{pLER}_{1}$ will be greater than $\mathrm{pLER}_{2}$, resulting in a greater weight for the usually larger value of $N f_{1} / N f_{\text {IC }}$ as compared to $N f_{2} / N f_{\text {IC }}$, which will tend to be smaller than one. In that case, FNER will be greater than LER.

We directly collected the $\mathrm{N}$ input data if the publication stated that fertilizer $\mathrm{N}$ was applied to the whole intercrop. However, if fertilizer $\mathrm{N}$ was applied separately to maize and soybean strip, the total $\mathrm{N}$ input for whole intercropping $\left(\mathrm{Nf}_{\mathrm{IC}}\right)$ was calculated as follows:

$\mathrm{Nf}_{\mathrm{IC}}=\frac{N_{\text {intercrop } 1} \times \text { area }_{1}+N_{\text {intercrop } 2} \times \text { area }_{2}}{\text { area }_{1}+\text { area }_{2}}$

Where $N_{\text {intercrop1 }}$ and $N_{\text {intercrop2 }}$ are the amount of fertilizer N applied to maize and soybean strip (per unit area of each crop strip), and area $_{1}$ and area $_{2}$ are the areas of the strips growing maize and soybean, respectively.

The intercrop soybean yield proportion is defined as the intercrop soybean yield divided by the total grain yield of maize plus soybean.
Yield proportion $_{\text {intercrop soybean }}=\frac{\text { yield }_{\text {intercrop soybean }}}{\text { yield }_{\text {intercrop soybean }}+\text { yield }_{\text {intercrop maize }}}$

\subsection{Explanatory variables}

In the analyses, we used four explanatory variables, i.e. (1) continent, (2) soil organic matter as a proxy for soil fertility, (3) amount of fertilizer $\mathrm{N}$ applied to intercrops and sole crops, and (4) Temporal niche differentiation (TND). The first three variables were obtained directly from the publications, while TND was calculated according to Eq. (6) (Yu et al., 2015):

$\mathrm{TND}=\frac{P_{\text {system }}-P_{\text {overlap }}}{P_{\text {system }}}=1-\frac{P_{\text {overlap }}}{P_{\text {system }}}$

Where $P_{\text {overlap }}$ refers to the length of the period of overlap in the growing periods of maize and soybean in the maize/soybean intercropping, while $P_{\text {system }}$ refers to the duration of the whole period (from sowing of the first crop to harvest of the second). This index quantifies the proportion of time that the two species in the intercrop are growing separately, resulting in competitive relaxation due to the empty space left by the not yet sown or already harvested companion species. When TND is zero, the growing periods are identical, i.e. simultaneous intercropping, whereas, when TND is greater than 0 , there is temporal differentiation in growing periods, i.e. relay intercropping. If TND would be one, there would be no overlap (co-growth) at all, i.e. double cropping. Data on double cropping are not included in our analysis. Relay intercropping is often practiced where the growing season is longer than required for a sole crop but too short for double cropping (i.e. growing a second crop following harvest of the first crop).

\subsection{Statistical analysis}

Relationships between LER, pLER, FNER and explanatory variables were estimated via mixed effect modelling. All analyses were conducted in $\mathrm{R}$ ( $\mathrm{R}$ Core Team, 2013), using the $\mathrm{R}$ function lme (Pinheiro and Bates, 2000). Twelve mixed effects models were fitted to the data of the publications (models 1-14 in Table 2). Data records with missing values of a variable were excluded from analyses which required that variable. Model selection was conducted using the R functions AIC and Anova. Figures were made using $\mathrm{R}$ packages plotrix and graphics (Lemon, 2006; R Core Team, 2013). Similar to previous meta-analyses in intercropping, such as Yu et al. (2015, 2016a,b), we did not weight the studies according to measures of precision of the estimates extracted 
from the literature since this information was provided in a minority of the 88 publications. Excluding those papers would greatly reduce the number of records in the dataset, making results of further analyses more inaccurate than the analysis that we did. Unweighted regression provides valid and unbiased estimates so there is no problem with unweighted analyses in this sense, and unweighted analyses are not unusual in ecology and agriculture (McDaniel et al., 2014). Unweighted analyses have previously been found to be acceptable for analyzing intercropping data (McDaniel et al., 2014; Yu et al., 2015, 2016a,b). The advantage of an unweighted analysis is that a greater suite of source papers is suitable for analysis, thus increasing the population of studies that is available for meta-analysis.

We made funnel plots for both LER and FNER to determine whether there was evidence of publication bias (Philibert et al., 2014). A funnel plot is a scatterplot of effect sizes against measure of their precision (e.g. sample size or standard error) (Richard, 1984; Koricheva et al., 2013). Here, we plotted study size against LER and FNER of each publication to assess publication bias. Study size was defined as the total number of replicates over all the records per study (Yu et al., 2015; Martin-Guay et al., 2018).

\section{Results}

\subsection{Descriptive analysis}

\subsubsection{Distribution of LER and FNER}

First of all we checked whether there were differences in LER and FNER between studies originating from different databases. We found that the frequency distribution of LER values originating from "CNKI" and "WanFang" and those originating from "Web of Science" were similar (Appendix: Fig. S1a,b). The estimated cumulative probability distributions were not significantly different according the Kolmogorov-Smirnov test $(D=0.1665, P=0.091554$; Appendix: Fig. S1d). We therefore conclude that studies originating from CNKI, WanFang and Web of Science can be combined when assessing LER. There was no publication bias in our database according to funnel plots of study size against LER (Appendix: Fig. S7a). Five hundred and sixty six (566) out of 654 LER values $(86.5 \%)$ in the combined sample were greater than 1 . The average LER was $1.32 \pm 0.02$, while the median, the first and the third quartile LER values were 1.28, 1.11 and 1.44, respectively (Fig. 1a). Thus, maize/soybean intercropping is characterized by a substantial land use yield advantage.

The frequency distributions of FNER based on studies from "CNKI" and "WanFang" and based on "Web of Science" were similar (Appendix: Fig. S2a,b). The estimated cumulative probability distributions were not significantly different according the Kolmogorov-Smirnov test $(D=0.13753, P=0.07979$; Appendix: Fig. S2c). There was no publication bias in FNER according to the analysis with the funnel plot (Appendix: Fig. S7b). Out of 409 values of FNER, 376 were larger than one $(92 \%)$. The average value of FNER was $1.44 \pm 0.03$, while the median, the first and the third quartile FNER values were 1.47, 1.20 and 1.67 , respectively (Fig. 1b). The value of 1.44 means that to achieve the same yields as a unit area of intercropping using sole crops, $44 \%$ more fertilizer $\mathrm{N}$ would be needed. Thus maize/soybean intercropping is characterized by substantial savings in fertilizer use as compared to the sole crops. The average rate of $\mathrm{N}$ fertilization was $110.7 \pm 7.1 \mathrm{~kg} \mathrm{~N}$ $\mathrm{ha}^{-1}$ in sole maize, $56.0 \pm 4.3 \mathrm{~kg} \mathrm{~N}^{-1}$ in sole soybean and $79.2 \pm 4.9 \mathrm{~kg} \mathrm{~N} \mathrm{ha}^{-1}$ for intercropping system (Fig. 2a; Table S4). The average pLER of maize was $0.79 \pm 0.02$ and the average pLER of soybean was $0.56 \pm 0.02$ (Fig. $2 \mathrm{~b}$; Table S4). The high values of both LER and FNER indicate that the fertilizer saving is to a large extent due to increased productivity per unit land. However, in addition, the greater relative yield of maize than soybean also contributes to the high FNER: sole maize requires comparatively high $\mathrm{N}$ input, and this need is alleviated by intercropping with soybean. The calculations of FNER account for this fertilizer saving effect of intercropping. The average yield was $7.01 \pm 0.31 \mathrm{tha}^{-1}$ of sole maize, $5.97 \pm 0.31 \mathrm{t} \mathrm{ha}^{-1}$ of intercropped maize, $2.29 \pm 0.10 \mathrm{t}$ ha $^{-1}$ of sole soybean and $1.17 \pm 0.05 \mathrm{t} \mathrm{ha}^{-1}$ of intercropped soybean (Fig. 3a,b).

\subsubsection{Worldwide variation in LER and FNER of maize/soybean intercropping}

Maize/soybean intercropping is distributed over most of the world, including Asia, Africa, America, Europe and Australia, but unevenly (Fig. 4). The total database included 464 valid records from Asia (355 of those from China), 106 from Africa, 10 from Australia, 63 from North America, 4 from South America and 11 from Europe (Fig. 5a; model 3 in Table 2). The LER was greatly different among continents: the average LER was $1.48 \pm 0.087$ in Europe, $1.41 \pm 0.038$ in Asia (except China), $1.38 \pm 0.051$ in Africa, $1.06 \pm 0.066$ in North America, $1.04 \pm 0.17$ in South America, and $0.95 \pm 0.13$ in Australia. LER was significantly greater than 1 in most regions except Australia, North America and South America. In China, the average LER was $1.35 \pm 0.03$. In other words, maize/soybean intercropping increased land use efficiency across different regions of the world, but to varying extent.

The ranking of FNER from different continents was South America (average $1.65 \pm 0.23$ ), North America (average $1.56 \pm 0.09$ ), Africa (average $1.54 \pm 0.08$ ), Europe (average $1.47 \pm 0.19$ ), Asia except China (average $1.38 \pm 0.06$ ) and Australia (average $0.94 \pm 0.17$ ). The average FNER in China was $1.48 \pm 0.04$. FNER was significantly larger than 1 in all continents except in Australia (Fig. 5b; model 4 in Table 2), indicating intercropping maize and soybean saved fertilizer at the land use level in most continents.

\subsection{Effect of different factors on LER and FNER}

TND varied substantially; from 0 up to 0.81 (Appendix: Fig. S1) and
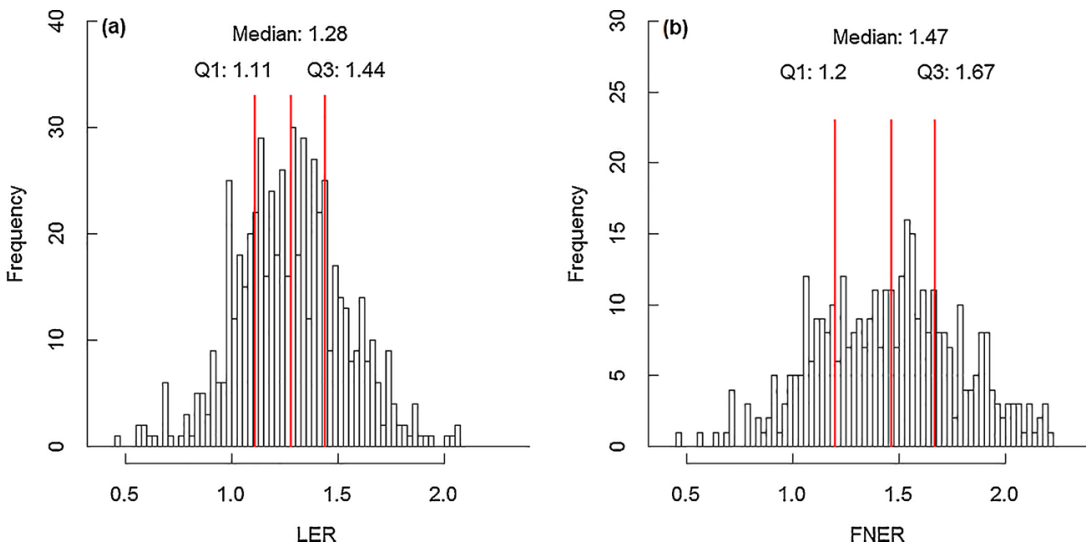

Fig. 1. Frequency distribution of LER (a) and FNER (b). Vertical lines in panels of frequency distribution (a-b) indicate the first quartile (Q1), median and the third (Q3) quartile of LER FNER. Frequency distribution of LER and LER were estimated by two mixed effects models: model $1: \mathrm{LER}_{\mathrm{ijk}}=$ $\beta_{0}+\mathrm{a}_{\mathrm{i}}+\mathrm{b}_{\mathrm{ij}}+\varepsilon_{\mathrm{ijk}}$ and model 2: $\mathrm{FNER}_{\mathrm{ijk}}=\beta_{0}+\mathrm{a}_{\mathrm{i}}+\mathrm{b}_{\mathrm{ij}}+\varepsilon_{\mathrm{ijk}}$, respectively. 

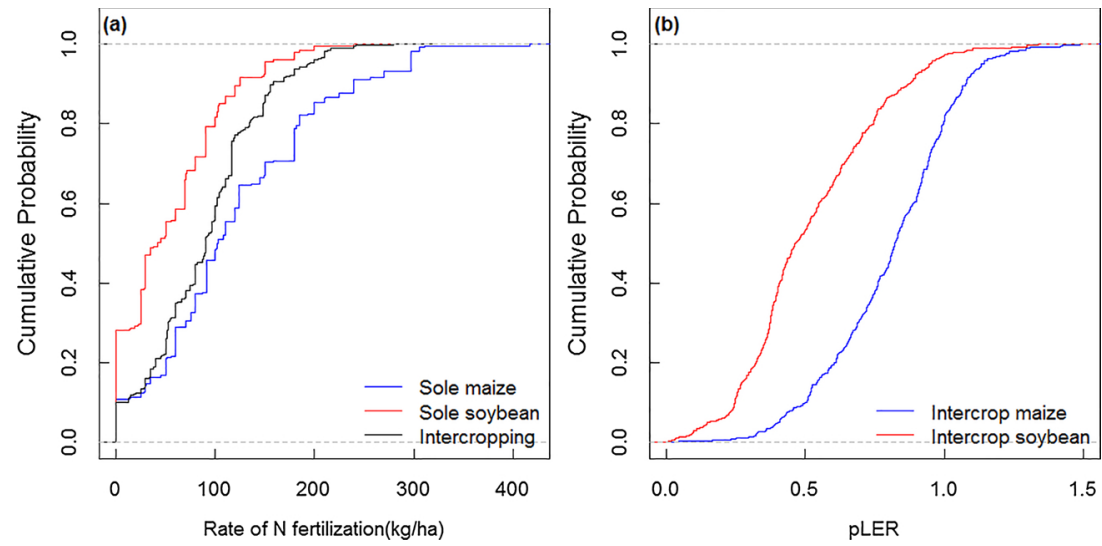

Fig. 2. Cumulative probability distributions of $\mathrm{N}$ fertilizer input (a), and pLER (b).
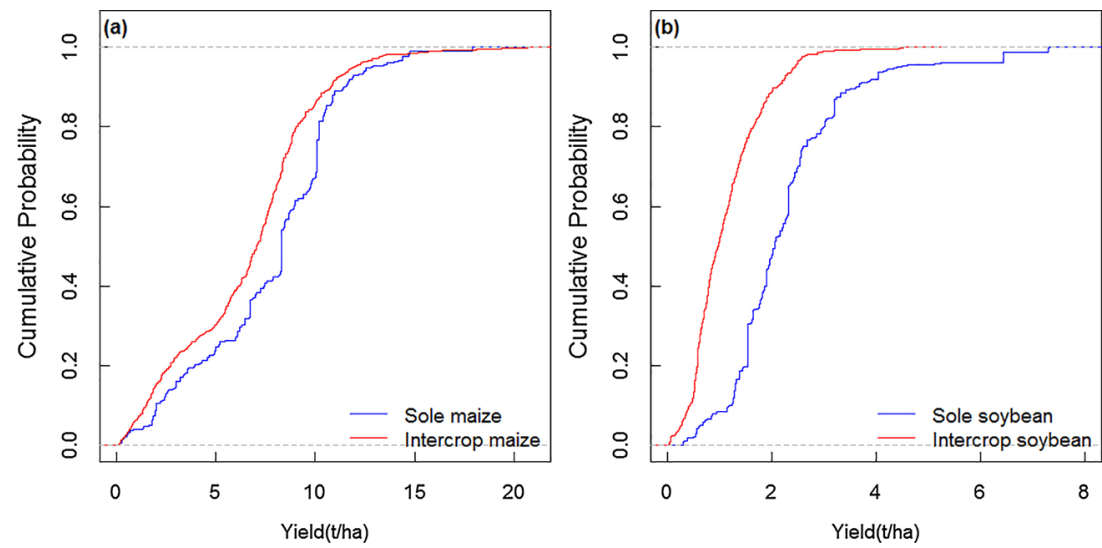

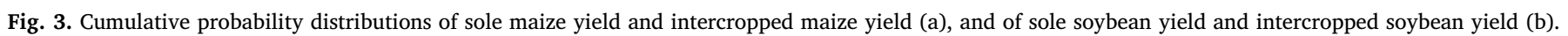

there was a significant relationship between LER and TND with a slope of $0.214 \pm 0.011$ (units of LER per unit of TND) and an intercept (LER at TND $=0$ ) of $1.25 \pm 0.03$ (Fig. $6 \mathrm{a}, P=0.0043$; model 5 in Table 2). The significant positive slope of the relationship indicates that relay intercropping has a substantially greater land equivalent ratio than simultaneous intercropping, with LER increasing as the period of cogrowth becomes shorter and the two crops species are growing alone for a greater proportion of their growing periods. There was no clear global pattern in TND, i.e. there was no global pattern in the use of relay intercropping (Appendix: Fig. S3).

FNER had a quadratic relationship to TND with a maximum at a TND of 0.49 (Fig. $6 \mathrm{~b}, P=0.0413$; model 6 in Table 2). Relay intercropping was always configured as row or strip intercropping, and never as fully mixed intercropping.

The LER increased by $0.00396 \pm 0.0016$ units per $\mathrm{g} / \mathrm{kg}$ increase in soil organic matter with an LER intercept of $1.31 \pm 0.03$ (Fig. 7a, $P=0.0143$; model 7 in Table 2). We found no significant response of FNER to soil organic matter (Fig. $7 \mathrm{~b}, P=0.2185$; model 8 in Table 2).

\subsection{Effect of fertilizer $N$ on $L E R$}

Total LER and pLER $_{1}$ (maize) did not change with additional fertilizer N (Fig. 8a, $P=0.8914$, and Fig. $8 \mathrm{~b}, P=0.6322$; models 9 and 10 in Table 2, respectively). However, $\mathrm{pLER}_{2}$ (soybean) decreased with fertilizer N (Fig. 8c, $P=0.0131$; model 11 in Table 2, $\beta_{1}=-0.000583$ ). Thus, with greater input of fertilizer $\mathrm{N}$, soybean relative yield decreased while maize relative yield and relative yield total (LER) did not respond significantly. The proportional contribution of soybean to the overall grain yield decreased strongly with fertilizer $\mathrm{N}$ input (Fig. 8d, $P<0.001$; model 12 in Table $2, \beta_{1}=-0.000946$ ).

There was no significant difference in LER between different fertilizer N situations. The average LER was $1.34 \pm 0.02$ when both intercropped soybean and sole soybean did not receive fertilizer $\mathrm{N}$ and $1.33 \pm 0.02$ when intercropped soybean and sole soybean both received fertilizer $\mathrm{N}$ input, (Fig. 9a). In the far majority of cases, if fertilizer $\mathrm{N}$ was given to soybean, the amount was the same in the sole crop and the intercrop, but in 10 cases out of 328, it was less in the intercrop than in the sole crop. The average FNER was $1.51 \pm 0.08$ when both intercropped soybean and sole soybean received no fertilizer $\mathrm{N}$ input, and $1.45 \pm 0.03$ when intercropped soybean and sole soybean received the fertilizer $\mathrm{N}$ input (Fig. 9b).

\section{Discussion}

Results of this global meta-analysis show that maize/soybean intercropping has a high LER, from 1.32 with simultaneous intercropping (two species sown and harvested simultaneously) to values in the range 1.25-1.46 with relay intercropping. The high LER means that intercropping uses less land for the same yields, or - alternatively - total production may be increased by using intercropping on the same land area. The FNER was 1.31 for simultaneous intercropping, while a higher value of 1.71 was obtained in relay intercropping. This result indicates that there is major niche complementarity for $\mathrm{N}$ uptake in maize/soybean intercropping, and especially in relay intercropping.

These results are in line with those of Yu et al. (2015) who found that the worldwide average LER in intercropping is $1.22 \pm 0.02$ while LER increased with TND. Likewise, Martin-Guay et al. (2018) found that the worldwide average LER is $1.30,95 \%$ CI $[1.27,1.32]$. In our study, average LER of maize/soybean intercropping was $1.32 \pm 0.02$. This means a considerable land sparing potential for two of the major food crops in the world. The results are also consistent with those of Yu et al. (2015) in finding high land equivalent ratios in Asia, and 


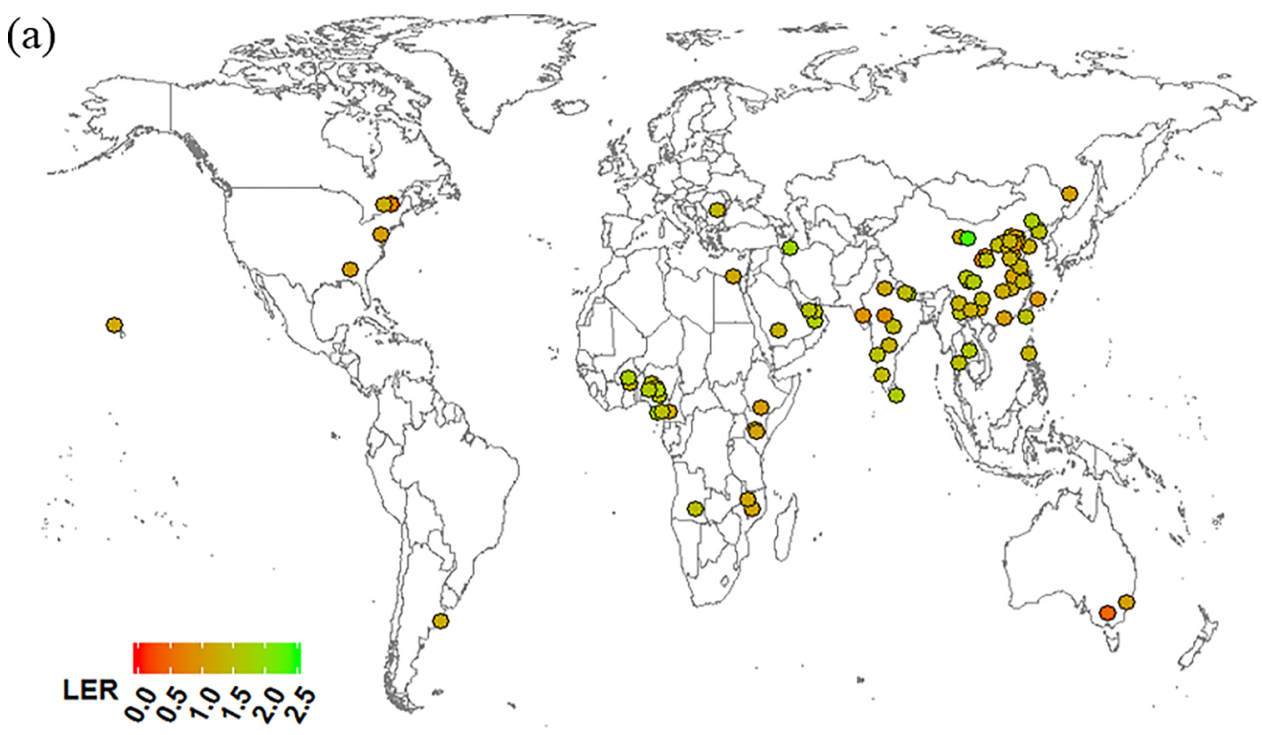

(b)

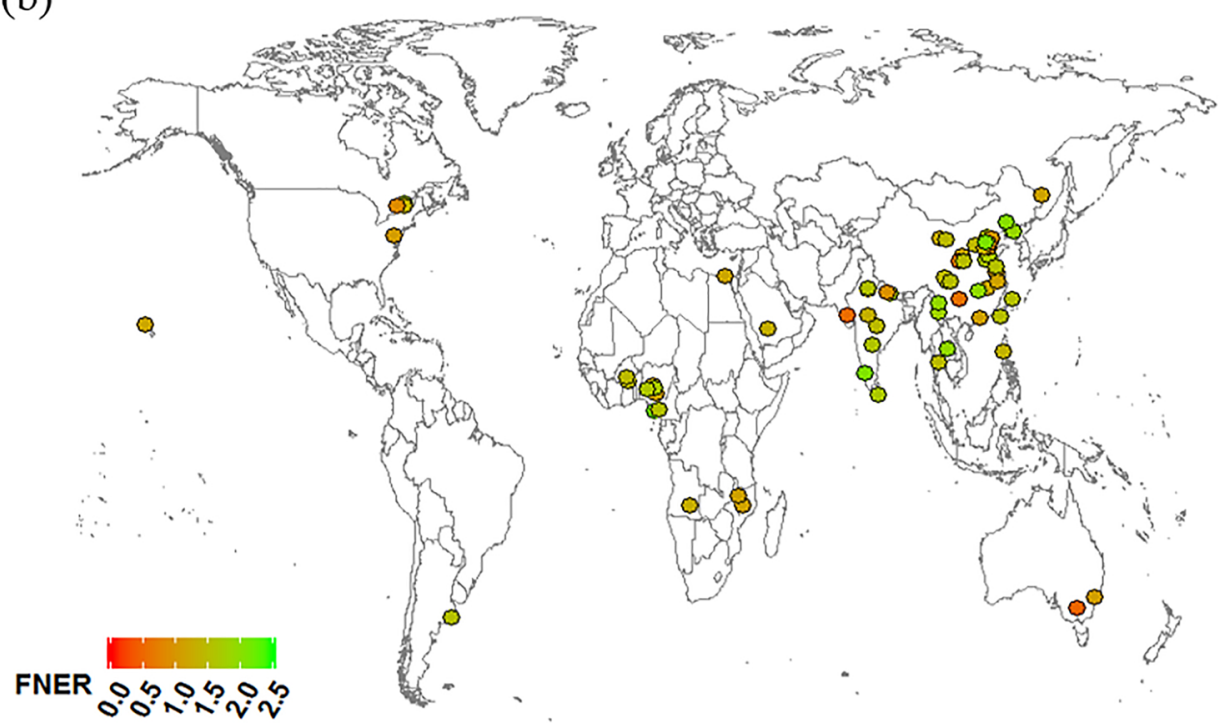

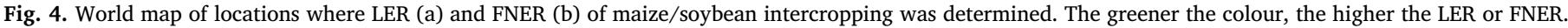
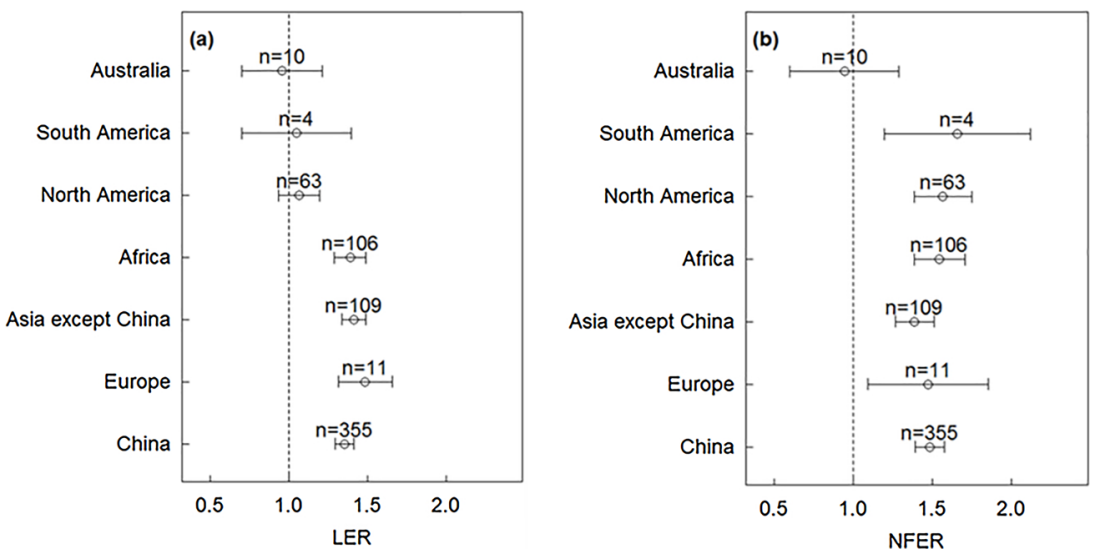

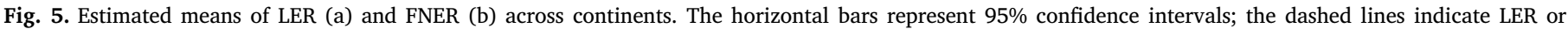
FNER $=1$. Means of LER and FNER across continents were estimated with the models 3 and 4 in Table 2. 

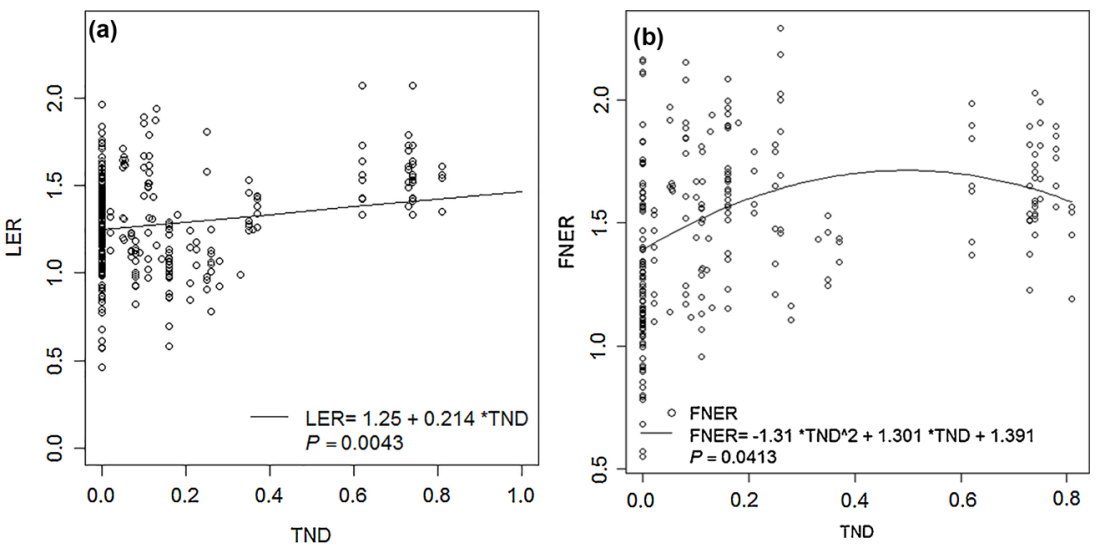

Fig. 6. Relationship between LER and TND (a), FNER and TND (b). $P$-values relate to the slopes of the regressions. Relationships between TND and LER and FNNFER were estimated by two mixed effects models: model 5: $\mathrm{LER}_{\mathrm{ijk}}=\beta_{0}+\beta_{1}{ }^{*} \mathrm{TND}_{\mathrm{ijk}}+\mathrm{a}_{\mathrm{i}}+\mathrm{b}_{\mathrm{ij}}+\varepsilon_{\mathrm{ijk}}$ and model 6:

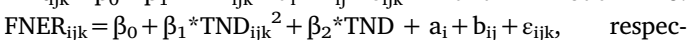
tively. particularly in China, where strip relay intercropping has been popular with farmers and has been extensively studied by researchers (Zhang and Li, 2003; Hong et al., 2017). The meta-analysis of Yu et al. (2015) contained 7 publications on maize/soybean intercropping that are also included in the current analysis. The results of our analysis were not changed importantly if the 7 papers in common were omitted, so the results of our study provide independent confirmation of the findings of Yu et al. (2015) (Appendix: Fig. S6, S7).

The high LER of intercropping suggests that this is not only a traditional mode of agriculture for the past but also a promising practice that could improve land productivity and decrease the environmental impacts of fertilizer $\mathrm{N}$ spills over the world in the future. The high values of both LER and FNER indicate that the fertilizer saving is to a large extent due to increased productivity per unit land. The fact that the relative yield of maize was greater than that of soybean also contributed to the high FNER: sole maize required comparatively high $\mathrm{N}$ input, and this need was alleviated by intercropping with soybean. Our results about different fertilizer $\mathrm{N}$ situations indicated that the values of LER and FNER were unaffected by $\mathrm{N}$ fertilization of the soybean (Fig. 9). Our analysis shows that the fertilizer savings are mainly the consequence of concentrating production on less land with fertilizer inputs that are intermediate between the sole crops. These important results are beneficial for developing countries and developed countries alike.

Achieving high production with low input is very important for developing countries where economic access to fertilizer $\mathrm{N}$ is limited (Snapp et al., 2010; Himmelstein et al., 2017). Cereal/legume intercropping has an advantage especially in low input systems (Searle et al., 1981). It is estimated that soybean can fix about 39 to $182 \mathrm{~kg} \mathrm{~N} \mathrm{ha}^{-1}$ (Peoples et al., 2009). When legumes are intercropped with cereals, they fix more nitrogen (per plant) than when they are grown as a sole crop, because of the strong competition for $\mathrm{N}$ from the cereal (Li et al.,
2016). Thus, both the cereal and legume can obtain sufficient nitrogen resources for their growth under soil $\mathrm{N}$ supply levels that would be limiting to the cereal. In a high $\mathrm{N}$ environment, legumes are often shaded by the maize, resulting in shade avoidance responses and low yield (Yang et al., 2014). This phenomenon also emerged in our metaanalysis (Fig. 8d). This negative effect of cereals on legumes can be mitigated by sowing the legume before the cereal (Yu et al., 2016a,b). Further research is needed to identify optimal combinations of planting configuration, sowing dates and fertilizer to achieve high yields and high $\mathrm{N}$ use efficiency in intercropping, and exploit biological $\mathrm{N}$ fixation without driving the system to very resource poor low yielding conditions. This meta-analysis shows that maize/soybean intercropping has the potential to achieve high LER and FNER at moderate $\mathrm{N}$ input levels.

The FNER of maize/soybean intercropping system was 1.44 so $44 \%$ more $\mathrm{N}$ would be needed to achieve the same yields as a unit area of intercrop using sole crops. It is widely recognized that intercropping of cereals and legumes can enhance $\mathrm{N}$ use efficiency (Zhou et al., 2000; Chen et al., 2017). Many experiments have found that intercrops can absorb more $\mathrm{N}$ than sole crops (Li et al., 2001a, 2013) and total $\mathrm{N}$ uptake by intercropped wheat and soybean together is significantly greater than the mean of the sole crops (Li et al., 2001a). Compared with cereal monoculture, cereal/legume intercropping acquires more $\mathrm{N}$, and part of it from air, which is a pathway not competing with cereal $\mathrm{N}$ acquisition (Fan et al., 2006). Intercropping thus offers the potential for enhanced $\mathrm{N}$ use efficiency and reduced environmental pollution associated with high $\mathrm{N}$ input.

Our results show that the LER in maize/soybean intercropping increases with TND, indicating that the land sparing by intercropping was greater in relay intercropping than in simultaneous intercropping. The reason is that species with a similar spatial and/or temporal niche tend to compete intensively, which would reduce biomass and production of the relatively weaker competitor (Yang et al., 2014; Yu et al., 2016a, b).
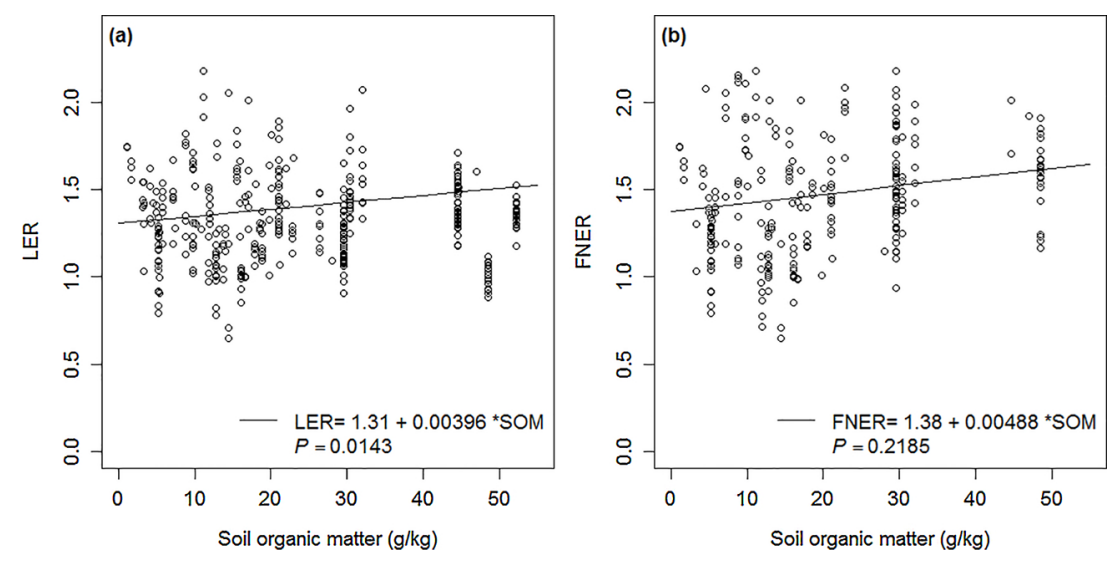

Fig. 7. Scatter plots of LER against soil organic matter (a) and FNER against soil organic matter (b). $P$-values relate to the slopes of the regressions. Relationships between soil organic matter and LER and FNER were estimated by two mixed effects models: model 7: $\mathrm{LER}_{\mathrm{ijk}}=\beta_{0}+\beta_{1} * \mathrm{SOM}_{\mathrm{ijk}}+\mathrm{a}_{\mathrm{i}}+\mathrm{b}_{\mathrm{ij}}+\varepsilon_{\mathrm{ijk}}$ and model 8: $\mathrm{NFER}_{\mathrm{ijk}}=\beta_{0}+\beta_{1} * \mathrm{SOM}_{\mathrm{ijk}}+\mathrm{a}_{\mathrm{i}}+\mathrm{b}_{\mathrm{ij}}+\varepsilon_{\mathrm{ijk}}$, respectively. 

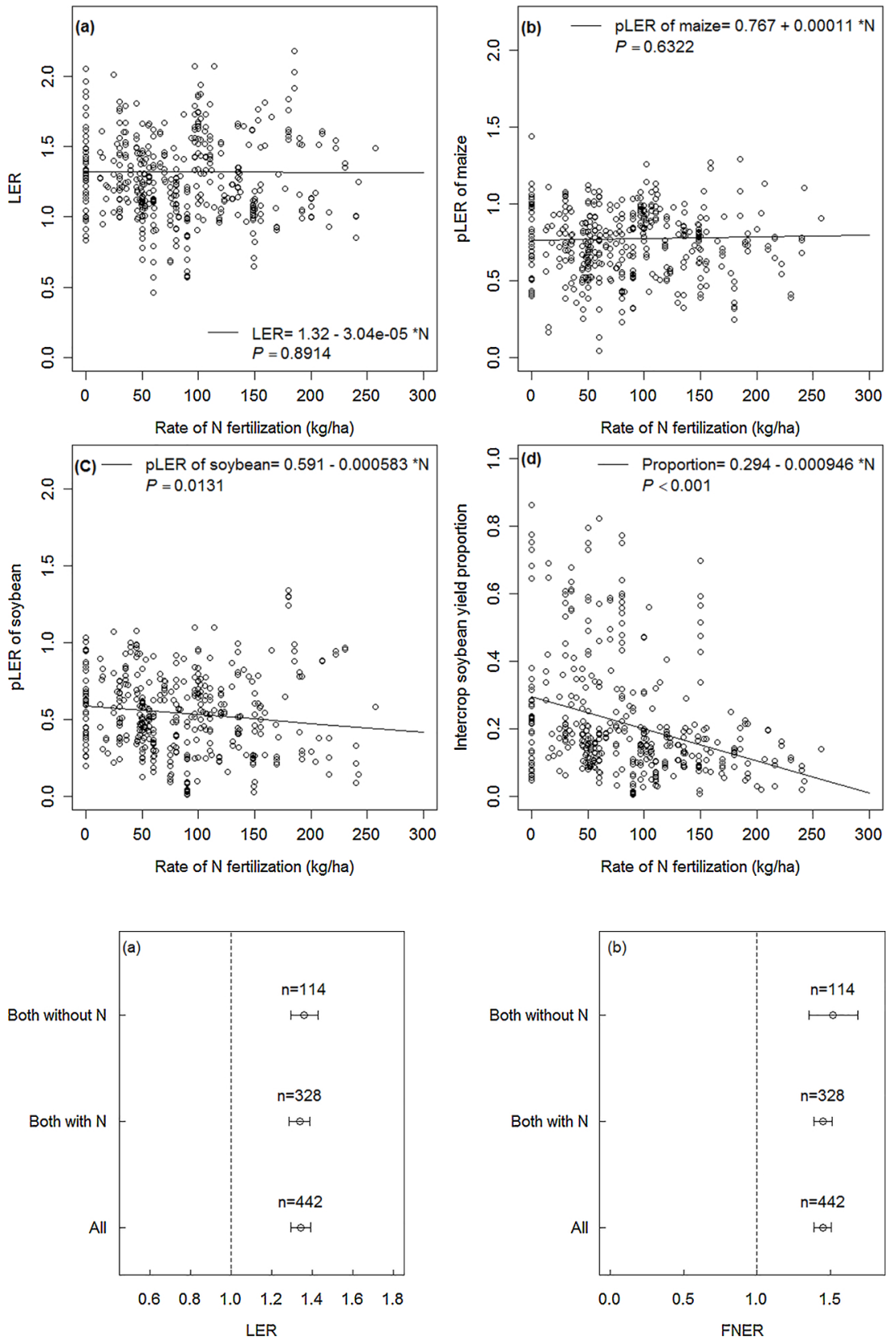

Fig. 8. Scatter plots of LER against rate of $\mathrm{N}$ fertilization (a) and pLER of maize against rate of $\mathrm{N}$ fertilization (b) and pLER of soybean against rate of $\mathrm{N}$ fertilization (c) and intercrop soybean yield proportion against rate of $\mathrm{N}$ fertilization. P-values relate to the slopes of the regressions. Relationships between rate of $\mathrm{N}$ fertilization and LER and $\mathrm{pLER}_{\text {maize }}$ and pLER $_{\text {soybean }}$ were estimated by two mixed effects models: model 9: $\quad \mathrm{LER}_{\mathrm{ijk}}=\beta_{0}+\beta_{1} * \mathrm{~N}_{\mathrm{ijk}}+\mathrm{a}_{\mathrm{i}}+\mathrm{b}_{\mathrm{ij}}+\varepsilon_{\mathrm{ijk}}$, model 10: $\mathrm{pLER}_{\text {maizeijk }}=\beta_{0}+\beta_{1} * \mathrm{~N}_{\mathrm{ijk}}+\mathrm{a}_{\mathrm{i}}+\mathrm{b}_{\mathrm{ij}}+\varepsilon_{\mathrm{ijk}}, \quad$ model 11 : pLER $_{\text {soybeanijk }}=\beta_{0}+\beta_{1} * \mathrm{~N}_{\mathrm{ijk}}+\mathrm{a}_{\mathrm{i}}+\mathrm{b}_{\mathrm{ij}}+\varepsilon_{\mathrm{ijk}}$, and model 12: Proportion $_{i j k}=\beta_{0}+\beta_{1} * N_{i j k}+a_{i}+b_{i j}+\varepsilon_{i j k}$.
Temporal niche differentiation can reduce the competition between two intercropped species. In relay intercropping, the later sown and harvested species, often maize, of which the growth has been previously depressed, can recover from negative competition and extend the total period for light capture of the system due to the differences in growing period between the species (Li et al., 2001b; Zhang and Li, 2003; Zhang et al., 2008a, b; Keating et al., 2014). Simultaneously, such a relay system can ensure that belowground resources, water and nutrients, are more completely used than they would be if only the early or late crop were grown as sole crops (e.g. Mao et al., 2012). Relay intercropping systems have greater total root length (i.e. uptake capacity) and root biomass than conventional intercropping system and are therefore efficient in absorbing nutrients and water (Gao et al., 2010; Cong et al., 2015). We impute from our results that part of the $\mathrm{N}$ transfer between legumes and cereals can happen within a season if the legume is grown earlier than the cereal (i.e. maize) such that $\mathrm{N}$ can be released from decomposing root mass and root nodules. In maize/soybean intercropping, TND and LER as well as FNER have a positive relationship.
According to the current analysis, the theoretical maximum LER at a temporal niche differentiation approaching 1 would be 1.56 .

The identified advantages in the use efficiency of land and fertilizer are major, but obtaining such yield benefits in actual agriculture in western mechanized agriculture will require dramatic advances in technology. As it stands, agriculture has gone a pathway of technological intensification with ever bigger scales and farm sizes, and reductions in labour per unit area and per unit product. To make ecological intensification by intercropping a reality, the spatial grain of management (sowing, managing, harvesting) needs to be reduced, while the labour input may not be increased if we are to maintain the high labour productivity of current agricultural methods. Technology progress and robotization in agriculture make such innovations in principle possible, but implementing a transition will require a joint effort of multiple stakeholders, including farmers, farm advisers, researchers, industry, and government. Indeed, authorities across the world are funding programs for sustainable intensification (e.g. the Horizon 2020 programme in Europe) and may keep doing so for the foreseeable future. 
The challenge for intercropping researchers is to draw up technology blueprints for intercropping and its mechanization that will inspire and attract the interest of parties in the agricultural economy and food and feed value chain. Another challenge for these researchers is to link up with societal stakeholders to catalyze a transition in agricultural technologies and practices.

\section{Conclusions}

In conclusion, maize/soybean intercropping is a promising practice to meet the challenge of sustainable development and food security. It is important not only for smallholder agriculture in developing countries, e.g. in Africa, to meet demands for calories and protein (Snapp et al., 2010), but also for organic farming and land sparing in developing countries (Fischer et al., 2008; Phalan et al., 2011). Maize/soybean intercropping can result in major increases in the efficiency of land and $\mathrm{N}$ fertilizer use, but this potential is largely untapped in contemporary farming in developed countries. Temporal niche differentiation, i.e. relay intercropping, has a positive effect on both LER and FNER. A multidisciplinary multi-actor approach will be needed, with involvement of stakeholders, to bring these potential advantages of intercropping of maize and soybean to practice.

\section{Declaration of Competing Interest}

The authors have declared that no conflict interests exist.

\section{Acknowledgements}

We acknowledge funding from the Chinese National Key R \& D Program (grant number 2017YFD0200200), the Chinese National Basic Research Program (NO. 2015CB150400) and the European Union's Horizon 2020 Programme for Research \& Innovation under grant agreement $n^{\circ} 727217$ (ReMIX: Redesigning European cropping systems based on species MIXtures).

\section{References}

Ainsworth, E.A., Yendrek, C.R., Skoneczka, J.A., Long, S.P., 2012. Accelerating yield potential in soybean: potential targets for biotechnological improvement. Plant Cell Environ. 35, 38-52.

Barona, E., Ramankutty, N., Hyman, G., Coomes, O.T., 2010. The role of pasture and soybean in deforestation of the Brazilian Amazon. Fnviron. Res. Lett. 5, 024002.

Chen, P., Du, Q., Liu, X.M., Zhou, L., Hussain, S., Lei, L., Song, C., Wang, X.C., Liu, W.G., Yang, F., Shu, K., Liu, J., Du, J.B., Yang, W.Y., Yong, T.W., 2017. Effects of reduced nitrogen inputs on crop yield and nitrogen use efficiency in a long-term maize-soybean relay strip intercropping system. PLoS One 12, e184503.

Clark, E.A., Francis, C.A., 1985. Transgressive yielding in Bean-Maize IntercropsInterference in time and space. Field Crops Res. 11, 37-53.

Cong, W., Hoffland, E., Li, L., Six, J., Sun, J., Bao, X., Zhang, F., van der Werf, W., 2015. Intercropping enhances organic carbon and nitrogen in soil. Glob. Chang. Biol. 21, 1715-1726.

Fan, F., Zhang, F., Song, Y., Sun, J., Bao, X., Guo, T., Li, L., 2006. Nitrogen fixation of faba bean (Vicia faba L.) interacting with a non-legume in two contrasting intercropping systems. Plant Soil 283, 275-286.

Fischer, J., Brosi, B., Daily, G.C., Ehrlich, P.R., Goldman, R., Goldstein, J., Lindenmayer, D.B., Manning, A.D., Mooney, H.A., Pejchar, L., Ranganathan, J., Tallis, H., 2008. Should agricultural policies encourage land sparing or wildlife-friendly farming? Front. Ecol. Environ. 6, 380-385.

Gao, Y., Duan, A., Qiu, X., Liu, Z., Sun, J., Zhang, J., Wang, H., 2010. Distribution of roots and root length density in a maize/soybean strip intercropping system. Agric. Water Manag. 98, 199-212.

Ghaffarzadeh, M., Prechac, F.G., Cruse, R.M., 1994. Grain yield response of corn, soybean, and oat grown in a strip intercropping system. Am. J. Altern. Agric. 9, 171-177.

Giller, K.E., Beare, M.H., Lavelle, P., Izac, A.M.N., Swift, M.J., 1997. Agricultural intensification, soil biodiversity and agroecosystem function. Appl. Soil Ecol. 6, 3-16.

Gliessman, S.R., 1983. Chapter V. Multiple Cropping Systems: a Basis for Developing an Alternative Agriculture. Publisher: Congress of the U.S. Office of Technology Assessment, pp. 69-83.

Good, A.G., Shrawat, A.K., Muench, D.G., 2004. Can less yield more? Is reducing nutrient input into the environment compatible with maintaining crop production? Trends Plant Sci. 9, 597-605.

Himmelstein, J., Ares, A., Gallagher, D., Myers, J., 2017. A meta-analysis of intercropping in Africa: impacts on crop yield, farmer income, and integrated pest management effects. Int. J. Agric. Sustain. 15, 1-10

Guo, J., Liu, X., Zhang, Y., Shen, J., Han, W., Zhang, W., Christie, P., Goulding, K.W.T. Vitousek, P.M., Zhang, F., 2010. Significant acidification in major Chinese croplands. Science $327,1008-1010$.

Hong, Y., Heerink, N., Jin, S., Berentsen, P., Zhang, L., van der Werf, W., 2017. Intercropping and agroforestry in China; current state and trends. Agric. Ecosyst. Environ. 244, 52-61.

Huang, C., Liu, Q., Heerink, N., Stomph, T., Li, B., Liu, R., Zhang, H., Wang, C., Li, X. Zhang, C., van der Werf, W., Zhang, F., 2015. Economic performance and sustainability of a novel intercropping system on the north China plain. PLoS One 10, e0135518.

Keating, B.A., Herrero, M., Carberry, P.S., Gardner, J., Cole, M.B., 2014. Food wedges: framing the global food demand and supply towards 2050. Glob. Food Sec. 3, $125-132$.

Koricheva, J., Gurevitch, J., Mengersen, K., 2013. Handbook of Meta-analysis in Ecology and Evolution. Princeton University Press.

Li, B., Li, Y., Wu, H., Zhang, F., Li, C., Li, X., Lamber, H., 2016. Root exudates drive interspecific facilitation by enhancing nodulation and $\mathrm{N}_{2}$ fixation. Proc. Natl. Acad. Sci. U. S. A. 113, 6496-6501.

Li, L., Sun, J., Zhang, F., Li, X., Yang, S., Rengel, Z., 2001a. Wheat/maize or wheat/ soybean strip intercropping I. Yield advantage and inter-specific interactions on nutrients. Field Crops Res. 71, 123-137.

Li, L., Sun, J., Zhang, F., Rengel, Z., Yang, S., 2001b. Wheat/maize or wheat/soybean strip intercropping. II. Recovery or compensation of maize and soybean after wheat harvesting. Field Crops Res. 71, 173-181.

Li, L., Zhang, L., Zhang, F., 2013. Crop mixtures and the mechanisms of over yielding. Encycl. Biodivers. 2, 382-395.

Li, Y., Yu, C., Cheng, X., Li, C., Sun, J., Zhang, F., Lambers, H., Li, L., 2009. Intercropping alleviates the inhibitory effect of $\mathrm{N}$ fertilization on nodulation and symbiotic $\mathrm{N}_{2}$ fixation of faba bean. Plant Soil 323, 295-308.

Liu, X., Zhang, Y., Han, W., Tang, A., Shen, J., Cui, Z., Vitousek, P., Erisman, J., Goulding, K., Christie, P., Fangmeier, A., Zhang, F., 2013. Enahncednitrogendeposition over China, Nature 494. pp. 459-462.

Lemon, J., 2006. Plotrix: a package in the red ligth district of R. RNews 6, 8-12.

Mao, L., Zhang, L., Li, W., van der Werf, W., Sun, J., Spiertz, H., Li, L., 2012. Yield advantage and water saving in maize/pea intercrop. Field Crops Res. 138, 11-20.

Martin-Guay, M.O., Paquette, A., Dupras, J., Rivest, D., 2018. The new green revolution: sustainable intensification of agriculture by intercropping. Sci. Total Environ. 615, 767-772.

Matson, P.A., Parton, W.J., Power, A.G., 1997. Agricultural intensification and ecosystem properties. Science 277, 504-509.

Mead, R., Willey, R.W., 1980. The Concept of a 'Land Equivalent Ratio' and advantages in yields from intercropping. Exp. Agric. 16, 217-228.

McDaniel, M.D., Tiemann, L.K., Grandy, A.S., 2014. Does agricultural crop diversity enhance soil microbial biomass and organic matter dynamics? A meta-analysis. Ecol. Appl. Publ. Ecol. Soc. Am. 24, 560-570.

Ngwira, A.R., Aune, J.B., Mkwinda, S., 2012. On-farm evaluation of yield and economic benefit of short term maize legume intercropping systems under conservation agriculture in Malawi. Field Crops Res. 132, 149-157.

Peoples, M.B., Brockwell, J., Herridge, D.F., Rochester, I.J., Alves, B.J.R., Urquiaga, S., Boddey, R.M., Dakora, F.D., Bhattarai, S., Maskey, S.L., Sampet, C., Rerkasem, B., Khan, D.F., Hauggaard-Nielsen, H., Jensen, E.S., 2009. The contributions of nitrogenfixing crop legumes to the productivity of agricultural systems. Symbiosis 48, 1-17.

Phalan, B., Onial, M., Balmford, A., Green, R.E., 2011. Reconciling food production and biodiversity conservation: land sharing and land sparing compared. Science 333, 1289-1291.

Philibert, A., Loyce, C., Makowski, D., 2014. Assessment of the quality of meta-analysis in agronomy. Agric. Ecosyst. Environ. 148, 72-82.

Pinheiro, J.C., Bates, D.M., 2000. Mixed-Effects Models in S and S-PLUS. Springer.

R Core Team, 2013. R: a Language and Environment for Statistical Computing. Foundation for Statistical Computing, Vienna, Austria.

Richard, J., 1984. Summing Up. Harvard University Press.

Rusinamhodzi, L., Corbeels, M., Nyamangara, J., Giller, K.E., 2012. Maize-grain legume intercropping is an attractive option for ecological intensification that reduces climatic risk for smallholder farmers in central Mozambique. Field Crops Res. 136, $12-22$.

Searle, P.G.E., Comudom, Y., Shedden, D.C., Nance, R.A., 1981. Effect of maize/legume intercropping systems and fertilizer nitrogen on crop yield sand residual nitrogen. Field Crops Res. 4, 133-145.

Snapp, S.S., Blackie, M.J., Gilbert, R.A., Bezner-Kerr, R., Kanyama-Phiri, G.Y., 2010. Biodiversity can support a greener revolution in Africa. Proc. Natl. Acad. Sci. U. S. A. 10, 20840-20845.

Sullivan, P., 2003. Intercropping principles and production practices. http://attra.ncat. org/attra-pub/PDF/intercrop.pdf.

Tilman, D., Cassman, K.G., Matson, P.A., Naylor, R., Polasky, S., 2002. Agricultural sustainability and intensive production practices. Nature 418, 671-677.

West, T.D., Griffith, D.R., 1992. Effect of strip-intercropping corn and soybean on yield and profit. J. Prod. Agric. 5, 107-110.

Wittwer, R.A., Dorn, B., Jossi, W., van der Heijden, M.G.A., 2017. Cover crops support ecological intensification of arable cropping systems. Sci. Rep. 7, 41911.

Wolff, X.Y., Coltman, R.R., 1989. Productivity under shade in Hawaii of five crops grown as vegetables in the tropics. J. Am. Soc. Hortic. Sci. 115, 175-181.

Wu, Y., Gong, W., Yang, F., Wang, X., Yong, T., Yang, W., 2016. Responses to shade and subsequent recovery of soya bean in maize-soya bean relay strip intercropping. Plant Prod. Sci. 19, 206-214.

Yang, F., Huang, S., Gao, R., Liu, W., Yong, T., Wang, X., Wu, X., Yang, W., 2014. Growth 
of soybean seedlings in relay strip intercropping system in relation to light quantity and red: far-red ratio. Field Crops Res, 155, 245-253.

Yu, Y., Stomph, T.J., van der Werf, W., 2015. Temporal niche differentiation increase the land equivalent ratio of annual intercrops: a meta-analysis. Field Crops Res. 184, 133-144.

Yu, Y., Makowski, D., Stomph, T.J., van der Werf, W., 2016a. Robust increases of land equivalent ratio with temporal niche differentiation: a meta-quantile regression. Agron. J. 108, 2269-2279.

Yu, Y., Stomph, T.J., Makowski, D., Zhang, L.Z., van der Werf, W., 2016b. A meta-analysis of relative crop yields in cereal/legume mixtures suggests options for management. Field Crops Res. 198, 269-279.

Zhang, F., Li, L., 2003. Using competitive and facilitative interactions in intercropping systems enhances crop productivity and nutrient-use efficiency. Plant Soil 248 ,
305-312.

Zhang, L., van der Werf, W., Zhang, S., Li, B., Spiertz, J.H.J., 2007. Growth, yield and quality of wheat and cotton in relay strip intercropping systems. Field Crops Res. 103, 178-188.

Zhang, W., Ma, W., Ji, Y., Fan, M., Oenema, O., Zhang, F., 2008a. Efficiency, economics, and environmental implications of phosphorus resource use and the fertilizer industry in China. Nutr. Cycl. Agroecosystems 80, 131-144.

Zhang, W., Tang, Y., Zhang, S., Zhang, F., Jiang, R., Cao, Y., 2008b. Problems faced by China's fertilizer industry in global food crisis and countermeasures for them. Mod. Chem. Ind. 28, 1-7.

Zhou, X., Madramootoo, C.A., MacKenzie, A.F., Kaluli, J.W., Smith, D.L., 2000. Corn yield and fertilizer $\mathrm{N}$ recovery in water-table-controlled corn-rye-grass systems. Eur. J. Agron. 12, 83-92. 